\title{
ERRORS IN LEARNING MATHEMATICAL ALGORITHMS IN SOLVING NUMERICAL AND ALGEBRAIC PROBLEMS
}

\author{
JOSÉ MARTÍNEZ ${ }^{\text {., ORLANDO GARCÍA }}{ }^{2}$ \& ROBERTO POVEDA ${ }^{3}$ \\ ${ }^{I}$ Basic science department. Universidad Santo Tomás, Bogotá. Colombia \\ ${ }^{2,3}$ Engineering Faculty, Universidad Distrital Francisco José de Caldas, Bogotá. Colombia
}

\begin{abstract}
This work aims to identify some frequent errors in the learning of mathematical algorithms in the resolution of numerical and algebraic problems in first semester students in the Administrative Sciences and Economics careers, applying a test at the beginning of the leveling course in Mathematics and thus identify the type of errors and their different classifications, finally, establish some guidelines that allow proposals to be made to overcome them. KEYWORDS: Errors, algorithms, numerical and algebraic problems
\end{abstract}

Received: Nov 24, 2020; Accepted: Dec 15, 2020; Published: Dec 23, 2020; Paper Id.: IJMPERDDEC202054

\section{INTRODUCTION}

The present investigation approaches according to its objectives the glance to the error as a source of information in the processes of learning of the same one, consequently, this investigation is born from the interest to make a detailed glance about the errors in the learning of mathematical algorithms in the resolution of numerical and algebraic problems in students of administrative and economic sciences who enter to the first semester in a private university in Bogota Colombia, where a course denominated module of leveling in mathematics is given to them, of which a significant sample was chosen for the accomplishment of the investigation. With this sample, a test was designed that allowed the elaboration of some categories of analysis according to Radazt (1980) and to establish in a meticulous way the errors and the frequency with which the students commit the different typologies of these in the resolution of arithmetic and algebraic problems.

Thus, this research intends to analyze the patterns of error committed by students of Administrative Sciences and Economics, allowing evidence of the systematic errors of inadequate conceptions of learning or poorly acquired processes, which provide clues about convenient strategies when carrying out the teaching and learning processes in university Mathematics, (Martínez 2015).

Besides, it seeks to identify deficiencies in basic concepts in mathematics (arithmetic and algebra) that are fundamental for the understanding of new conceptions of students in Administrative and Economic Sciences. These deficiencies have been evidenced in the leveling course in Mathematics oriented to the different careers and the level of desertion "possibly" by the mathematics courses in the first semesters.

For that reason, this research contributes with a conductive thread for future admissions to Administrative Sciences careers, that is to say, from the beginning it is possible to foresee mortality situations for new students, and 
thus look for methodological and didactic strategies in the leveling courses at the beginning of each semester, which can identify and eliminate possible failures caused by the mathematical error in those processes.

\section{METODOLOGY}

The established research design is mixed, that is, it allows a systematic combination of the quantitative and qualitative method in a single study to achieve a complete representation of the studied phenomenon, in such a way that the original structure and procedures are preserved, but with modifications. "modified form of mixed methods". (Chan, 2006 cited by Samperio, 2010).

The qualitative, as indicated by Bacherlat (1991), is intended to seek the accuracy of social measurements or indicators to generalize their results to broad populations or situations.

As for the qualitative aspect, it is to understand and interpret reality by the participating actors in the context studied (Gómez and Rico, 1998), which implies the implementation of two research dimensions that will allow us to respond to the principle of complementarity, given that the subject matter, the actors studied and the relatively small scale on which the research is conducted make the work relevant within the qualitative paradigm. For this reason, the final analysis will also be given fundamentally in this outline, of an exploratory type, since, according to what Hernández (2006) points out: "exploratory studies are carried out when the objective is to examine a topic or research problem that has been little studied, of which there are many doubts or which has not been addressed before (...) Exploratory studies serve to familiarize us with relatively unknown phenomena, to obtain information about the possibility of carrying out more complete research concerning a particular context, to investigate new problems, to identify promising concepts or variables, to establish priorities for future research, or to suggest statements and postulates" ( p. 100-103)

This exploratory study will also combine descriptive aspects, since descriptive studies seek, according to Hernández: "to measure or collect information independently or jointly on the concepts or variables to which they refer, that is, their objective is not to indicate how the measured variables are related" (Hernández, 2006, p.102). And the ultimate goal is basically to achieve the description of each one of those associated with the phenomenon being studied.

It should be clarified that in the present research no hypotheses were projected, since as pointed out by Hernández (2006: p.122) these are not formulated when the study is exploratory or of a descriptive type, except when the latter tries to predict a fact or data, which is not the case for the present research. In that order, the descriptive was relevant since it was possible to state qualitatively the process of the problem's resolution as well as to quantify the percentage of students who show an error when addressing the problem. Finally, we will work with a random sample corresponding to first semester students of the School of Administrative Sciences and Economics.

According to the above, the following phases of the research were developed:

- For the methodological work, initially, the first instrument was elaborated where it was put to consideration of internal pairs in the university and external teaching pairs of another university, then it was validated.

- The population was identified according to lists of each leveling course in mathematics, taking into account only those of administrative and economic sciences.

- Then proceeded and applied the test to the first semester students. 
- Following the order of the work, the instrument for analyzing the test results was made according to the categories proposed for this purpose, and then the analysis of the 65 tests, a representative sample of the Neos population for that semester II of 2014, approximately two months

- The information was then systematized to observe the qualitative and quantitative behaviour of the sample following what was established for this work.

\section{Population and Sample}

The population that participated in this research was 520 students of the second semester of the year 2019 of the Santo Tomas University, called Neo-Tomasinos of the Faculty of Administrative and Economic Sciences. A random selection was made to the group of students from the mentioned faculty, leaving 65 students as a significant sample to advance the research. This test has a $95 \%$ confidence level.

\section{Information Tools}

With this purpose, four instruments were designed through which the errors in the learning of mathematical algorithms in the resolution of numerical and algebraic problems present in the Neo-Tomasino students of Administrative and Economic Sciences were identified. The look that was looked for is raised from two levels of analysis, one macroscopic and another microscopic.

Try

The test was elaborated with 20 problems, which were submitted to two academic pairs, two teachers from the Department of Basic Sciences of the Santo Tomas University and two external teachers from the District University. This test had problems based on the minimum knowledge that a first-semester student entering the university should have clear to start his professional training.

\section{FACULTY OF ADMINISTRATIVE AND ECONOMIC SCIENCES}

\section{BASIC SCIENCE DEPARTMENT - MATHEMATICS}

NAME: CARREER AGE

Perform each of the indicated problems.

1. $4-3\{3+2(-1-3)-3(1-6)\}$

2. Calculate $(-2)^{0}-1-3^{2}$

3. $\frac{4}{3}+2+\frac{1}{3}$

4. $\left(\frac{1}{3}-1\right)^{-1}$

5. $3^{-\frac{1}{2}}+3^{-2}$

6. $\sqrt{81-16}$

7. $4+2 \sqrt{3}+2+3 \sqrt{3}-11$

8. Clear the value of $x$ in $y=\frac{5+x}{3}$

9. a. Find the value of $y$ in
14. If $x=-1, y=2, z=-3$ the value of the expression $x^{2}+y^{2}-z^{2}$ es:

15. $\sqrt{25+64}$

16. An expression equivalent to $\frac{1}{\sqrt{2^{4}}}$ es:

17. If José is $\mathrm{x}$ years old and Julia is 4 yea younger, how old is Alfredo in each case??

a. Alfredo is 1 year older than the average age c Jose and Julia

b. Alfredo is 2 years younger than five times th difference in the ages of Jose and Julia.

18. Find the $x$ value that satisfies the equatio $x^{2}=-x+2$ 


$$
-4 y+6=3 y-1
$$

b. The value of $x$ in $3 x=\frac{5}{2}$

10. $\left(\frac{2}{3} a^{2}\right)^{2}$

11. $(x+1)^{2}$

12. The irreducible fraction of $\frac{4}{12}$ es

13. Simplify $\frac{8 a+4 b}{4}$
19. A person wants to invest $\$ 20,000$ in tw companies so that the total income per year $\$ 1,440$. One company pays $6 \%$ per year: th other has a higher risk and pays $7.5 \%$ per yea How much should you invest in eac company?

20. You want to carpet a room that is 6 metes long, 4 meters wide, and 2.5 meters high. Ho' much carpet should you buy?

\section{ANALYSIS OF RESULTS}

\section{Numerical context of the test}

In this context, 10 problems were analyzed where the errors presented in the properties addition and multiplication, potentiation and rooting were reviewed, with 3, 3 and 4 problems respectively. Evidenting the presence of $67.19 \%$ of errors present in this context.

\section{Errors in the properties of addition and multiplication}

In the properties of addition and multiplication of the numerical context, $59.61 \%$ of students who took the test showed errors of some kind, the results obtained from the 65 tests taken were as follows.

Table 1: Results of errors in the numerical context of the addition and multiplication property

\begin{tabular}{|c|c|c|c|c|c|}
\hline Property & Problems & $\mathbf{C}_{\mathbf{1}}$ & $\mathbf{C}_{\mathbf{2}}$ & $\mathbf{C}_{\mathbf{3}}$ & $\mathbf{C}_{\mathbf{4}}$ \\
\hline \multirow{4}{*}{ Adition and multiplication } & 1 & 52 & 43 & 21 & 28 \\
\cline { 2 - 7 } & 3 & 49 & 49 & 37 & 24 \\
\cline { 2 - 6 } & 12 & 42 & 42 & 39 & 39 \\
\hline
\end{tabular}

In the property addition and multiplication of the numerical context and taking into account the sample of students who presented the test, it was possible to evidence that the error:

- Most frequent is $\mathrm{C} 1$, with $73.33 \%$ of recurrence.

- $\mathrm{C} 2$ has a recurrence of $68.71 \%$.

- $\quad$ C3 has a recurrence of $49.74 \%$.

- $\quad$ C4 has the lowest recurrence with $46.67 \%$.

\section{Errors in the Potentiation Property}

The empowerment property presented the highest presence of numerical context errors in the students who presented the test, with $71.53 \%$ in some typology of error; the results obtained from the tests performed were the following: 
Table 2: Error results in the numerical context of the property potentiation

\begin{tabular}{|c|c|c|c|c|c|}
\hline Property & Problems & $\mathbf{C}_{\mathbf{1}}$ & $\mathbf{C}_{\mathbf{2}}$ & $\mathbf{C}_{\mathbf{3}}$ & $\mathbf{C}_{\mathbf{4}}$ \\
\hline \multirow{2}{*}{ Potentiation } & 2 & 50 & 47 & 29 & 29 \\
\cline { 2 - 6 } & 4 & 58 & 59 & 40 & 34 \\
\cline { 2 - 6 } & 5 & 62 & 59 & 46 & 45 \\
\hline
\end{tabular}

In the property addition and multiplication of the numerical context and taking into account the sample of students who presented the test, it was possible to evidence that the error:

1. $\mathrm{C} 1$ has the highest recurrence with $87.17 \%$.

2. C2 has a recurrence of $84.61 \%$.

3. $\mathrm{C} 3$ has a recurrence of $58.97 \%$.

4. Less frequently it is $\mathrm{C} 4$, with a recurrence of $55.38 \%$.

\section{Errors in the property of the root}

The root property presents errors in the numerical context in the students who presented the test, with $69.61 \%$ in some typology of error; the results obtained from the tests performed were the following:

Table 3: Results of errors in the numerical context of the property

\begin{tabular}{|c|c|c|c|c|c|}
\hline \multirow{2}{*}{ Property } & Problems & $\mathbf{C}_{\mathbf{1}}$ & $\mathbf{C}_{\mathbf{2}}$ & $\mathbf{C}_{\mathbf{3}}$ & $\mathbf{C}_{\mathbf{4}}$ \\
\hline \multirow{3}{*}{ Filing } & 6 & 44 & 44 & 44 & 44 \\
\cline { 2 - 6 } & 7 & 50 & 50 & 41 & 41 \\
\cline { 2 - 6 } & 15 & 50 & 50 & 50 & 50 \\
\cline { 2 - 6 } & 16 & 44 & 44 & 39 & 39 \\
\hline
\end{tabular}

In the property of the numerical context and taking into account the sample of students who presented the test, it was possible to evidence the error:

- $\quad \mathrm{C} 1$ and $\mathrm{C} 2$ have the highest recurrence with $72.30 \%$.

- $\quad \mathrm{C} 3$ and C4 have a lower frequency, with a recurrence of $66.92 \%$

\section{Errors in the way of interpretation}

In the property of interpretation of the verbal context, $66.15 \%$ of students who took the test have errors of some kind, the results obtained from the 65 tests taken were as follows:

Table 4: Results of errors in verbal context and interpretation

\begin{tabular}{|c|r|r|r|r|r|}
\hline Form & Problem & $\mathbf{C}_{1}$ & $\mathbf{C}_{2}$ & $\mathbf{C}_{3}$ & $\mathbf{C}_{4}$ \\
\hline Interpret & 14 & 46 & 46 & 40 & 40 \\
\hline
\end{tabular}


In the property of interpretation of the verbal context and taking into account the sample of students who presented the evidence, it was possible to evidence that the error:

1. $\mathrm{C} 1$ and $\mathrm{C} 2$ are more frequent, with a $70.77 \%$ recurrence.

2. C3 and C4 present the lowest recurrence with $61.54 \%$.

Errors in the form of argument

By arguing in the verbal context $82.30 \%$ of students who took the test had errors of some kind, the results obtained from the 65 tests taken were as follows:

Table 5: Results of verbal errors in argumentation

\begin{tabular}{|r|r|r|r|r|r|}
\hline Form & Problem & $\mathbf{C}_{\mathbf{1}}$ & $\mathbf{C}_{\mathbf{2}}$ & $\mathbf{C}_{\mathbf{3}}$ & $\mathbf{C}_{\mathbf{4}}$ \\
\hline Argue & 20 & 58 & 58 & 49 & 49 \\
\hline
\end{tabular}

In the way of arguing in the verbal context and taking into account the sample of students who presented the evidence, it was possible to evidence that the error was made:

1. Más frecuente sonC $_{1} \mathrm{y} \mathrm{C}_{2}$, con un $89.23 \%$ de recurrencia.

2. $\mathrm{C}_{3}$ y $\mathrm{C}_{4}$ presentan la menor recurrencia con un $75.38 \%$.

\section{CONCLUSIONS AND RECOMENDATIONS}

- Achieving absolute clarity in relation to the errors present in the test can become a complex task that demands, among other experiences and training, however, in research such as this, such a look is necessary. In this case it is useful insofar as it allows for the understanding of errors made by the Neo-Tomasino students of the faculty of economic and administrative sciences who presented the test, thus allowing for a proper evaluation of the errors presented here.

- Based on the results obtained in the research, it is evident that the $\mathrm{C} 1$ error in the arithmetic, algebraic and verbal contexts is the most recurrent with $86.07 \%$ in the Neo-Tomasino students of the Faculty of Economic and Administrative Sciences. Where the bad use of writing and lack of knowledge of mathematical language was detected; which does not allow progress in the solution of a problem.

- There is evidence of poor learning of facts, skills and previous concepts, because it was found lack of knowledge about content and procedures in mathematical algorithms in solving numerical and algebraic problems. That is, $85.15 \%$ of the Neo-tomasino students of administrative sciences and economics who presented the test make the $\mathrm{C} 2$ error.

- In the Neo-tomasino students of administrative sciences and economics who presented the test, some aspects of the content or of the solution process that inhibit the processing of new information persist. These errors were evident in the different contexts, with a recurrence of $67.30 \%$,

- The $\mathrm{C} 4$ error, although it is the least recurrent in the arithmetic, algebraic and verbal contexts, is very high; because $65.30 \%$ of Neo-Tomasino students in the faculty of economic and administrative sciences commit it. This is due to the poor application of rules or strategies when solving a problem. 
- It is known beforehand that the teaching of Mathematics is a very complicated practice, which does not allow a fixed process or a straight line, and therefore it is not possible for the time being a methodological process that allows to treat the error in mathematics in the same progress of the teaching-learning of the same, nor are there strategies that are well suited for each situation where the mathematical error is typified by a student and give a solution to it. For this reason, and as a logical suggestion, teachers who give guidance in basic mathematics to university students have the duty to work continuously on the error, that is, to give the error a presence in the classroom for the development of the class, intentionally producing the error so that the student can reach his own conjectures and conclusions, since they have already had training in certain subjects of basic mathematics, forcing him to return to previous well-defined schemes.

- On the other hand, it is also important to make this research known to the department of basic sciences in order to socialise the results with all the teachers in the area of mathematics, even though the director is aware of this work, thus motivating the teachers to give talks, Workshops that allow the study of mathematical errors to permeate the resolution of arithmetic and algebraic problems, not only in Neos but also in each of the students in the higher courses taught in the faculty of economic and administrative sciences, since there are previous concepts of basic mathematics that should be used when solving a specific problem.

\section{REFERENCES}

1. Bachelard, G. (1991). La formación del espiritu cientifico. Contribución a un psicoanálisis del conocimiento objetivo. México: Siglo XXI.

2. Gómez P y Rico (1998). (Editores) Educación Matemática. México: Grupo Editorial Iberoamérica, pp. 69 - 108.

3. Hernández R., y Otros (2006) Metodología de la investigación. México, Mc Graw Hill.

4. Martínez J. (2015). Errores en el aprendizaje de algoritmos matemáticos en la resolución de problemas numéricos y algebraicos en estudiantes neo-tomasinos de ciencias administrativas y económicas. Tesis de maestría. Universidad Santo Tomas

5. Radatz, H. (1980). Students' errors in the mathematical learning process: a survey. For the Learning of Mathematics, $V .1, N^{o}$ 1, pp. $16-20$. 

